\title{
Rheological and textural studies of fresh and freeze-thawed native sago starch-sugar gels. II. Comparisons with other starch sources and reheating effects
}

\begin{abstract}
The viscoelastic and textural properties of freshly prepared and freeze-thawed sago starchsugar gels were studied in comparison with other native starches from corn, wheat, tapioca, and potato. The gelatinisation and retrogradation properties of starches were studied using a DSC while the pasting properties of starch-sugar mixtures during the cooking period were studied using a starch pasting cell. The freeze-thaw stability of gels was evaluated by gravimetric measurements of the water of syneresis. The different starches gave properties which varied following to their botanical sources. High-amylose cereal starches (wheat and corn) produced harder gels, while low-amylose root starch (tapioca) produced softer gels. Sago and potato gels showed close similarities in their viscoelastic and textural characteristics. Although the freeze-thaw cycle greatly increased the viscoelasticity and hardness of these two gels, reheating at high temperature significantly reduced these negative effects and resulted in partial recovery of the gel structures. Sago starch produced gels with very low syneresis and high cohesiveness, implying its potential use as a gelling agent in the frozen food industries.
\end{abstract}

Keyword: Sago starch; Gel; Texture; Rheology; Freeze-thaw; Syneresis 